\title{
Erratum to: Cooperativity between fluorine-centered halogen bonds: investigation of substituent effects
}

\author{
Mehdi D. Esrafili • Fariba Mohammadian-Sabet • \\ Parvin Esmailpour • Mohammad Solimannejad
}

Published online: 16 November 2013

(C) Springer-Verlag Berlin Heidelberg 2013

Erratum to: Journal of Molecular Modeling

DOI 10.1007/s00894-013-2032-4

During the submission of the corrected proof file, an unintentional error occurred by our carelessness and lack of attention. In the original paper, the corresponding author's surname is incorrect. In this erratum, we state the correct version of the corresponding author's name is "Mehdi D. Esrafili".

The online version of the original article can be found under doi:10.1007/ s00894-013-2032-4.

M. D. Esrafili $(\bowtie) \cdot$ F. Mohammadian-Sabet • P. Esmailpour Laboratory of Theoretical Chemistry, Department of Chemistry, University of Maragheh, P.O. Box: 5513864596, Maragheh, Iran e-mail: esrafili@maragheh.ac.ir

M. Solimannejad

Quantum Chemistry Group, Department of Chemistry, Faculty of

Sciences, Arak University, Arak 38156-8-8349, Iran 